\title{
Performance Analysis of Free Space Optical Link Under Various Attenuation Effects
}

\author{
Gaurav Soni \\ Department of Electronics and Communication Engineering, Amritsar College of Engineering \& Technology, Amritsar, India \\ Email address: \\ gaurav.ece@acetedu.in \\ To cite this article: \\ Gaurav Soni. Performance Analysis of Free Space Optical Link Under Various Attenuation Effects. Science Journal of Circuits, Systems and \\ Signal Processing. Vol. 7, No. 2, 2018, pp. 43-47. doi: 10.11648/j.cssp.20180702.11
}

Received: December 17, 2017; Accepted: January 8, 2018; Published: March 27, 2018

\begin{abstract}
Free Space Optics (FSO) is useful where a fiber optic cable is impractical. It is similar to fiber optic communications in that data is transmitted by modulated laser light. Instead of containing the pulses of light with in a glass fiber, these are transmitted in a narrow beam through the atmosphere. This article discusses the main architectural details of the FSO communication system.. The major FSO Parameters discussed are wavelength selection, features of different wavelength windows and optical channel model. The article investigates the Performance of Free Space Optical Link under Various Attenuation Effects like rain, fog using Optiwave.
\end{abstract}

Keywords: Free Space Optics (FSO), Attenuation, Rain Attenuation

\section{Introduction}

The block diagram of a typical terrestrial FSO Link is shown in Figure 1. Like any other communication technologies, the FSO essentially comprises of three parts: the transmitter, the channel and the receiver.

The primary duty of the transmitter is to modulate the source data onto optical carrier then the output will passed through the air, space or vaccum and that will received by the receiver. The source data is in the binary form and converted to optical pulses by the transmitter [7-8]. Modulation can be of many types as onoff keying (OOK), pulse position modulation (PPM), differential phase shift keying (DPSK), differential quadrature phase shift keying (DQPSK) and subcarrier intensity modulation (SIM) [1]. The modulator is used to achieve high data rates by varying phase, frequency and amplitude, used to carry out modulation. The modulation is achieved by varying the driving current of the optical source directly in sympathy with the data to be transmitted or by the Mach-Zehnder (SMZ) Interferometer [8]. The driver circuit is used to vary driver current in accordance with input data, so that binary signal can be modulated or converted to optical pulses.. The $1550 \mathrm{~nm}$ band is attractive for a number of reasons as they provide larger range, high data rate, eye safety (about 50 times more power can be transmitted at $1550 \mathrm{~nm}$ than at $850 \mathrm{~nm})$, reduced solar background and scattering in light haze/fog. The transmit telescope collects the light, collimates it and directed towards the receiver telescope at the other end of the channel [8]. Atmospheric channel is free space link which can be $2-3 \mathrm{kms}$ long. As it is open channel so there are number of factors that affect the link like its data rate, long range connectivity and error rate also. The main factors that must be considered while establishing a link are: absorption, turbulence, scattering and beam divergence. Other source of attenuation is sunlight; the link can go blank if sun goes exactly behind the transmitter. Dust particles in the atmosphere, snow, fog, rain and precipitation can disturb the link \& affects the bit error rate (BER). It contains a telescope fitted with a lens that collects maximum light to provide maximum power to photo detector also optical filter is used to reject some unwanted wavelengths or noise that gets added during reception of the signal. The photodetectors are Avalance Photo Diodes (APD) or P-I-N diodes. APDs used are highly sensitive and needs 100-200 volt in reverse bias for their operation. These can detect visible and near IR wavelengths if silicon material is used. PIN diodes are used where high voltage detection is needed, also these have fast switching speeds but their use is limited for shorter distances. These are less expensive and are generally used for longer wavelengths. These diodes can detect different wavelengths like PIN (InGaAs) can detect 1550nm and Si can detect up to $1.1 \mu \mathrm{m}$. Post detection processor carries out necessary amplification and signal processing to generate error free signal. 


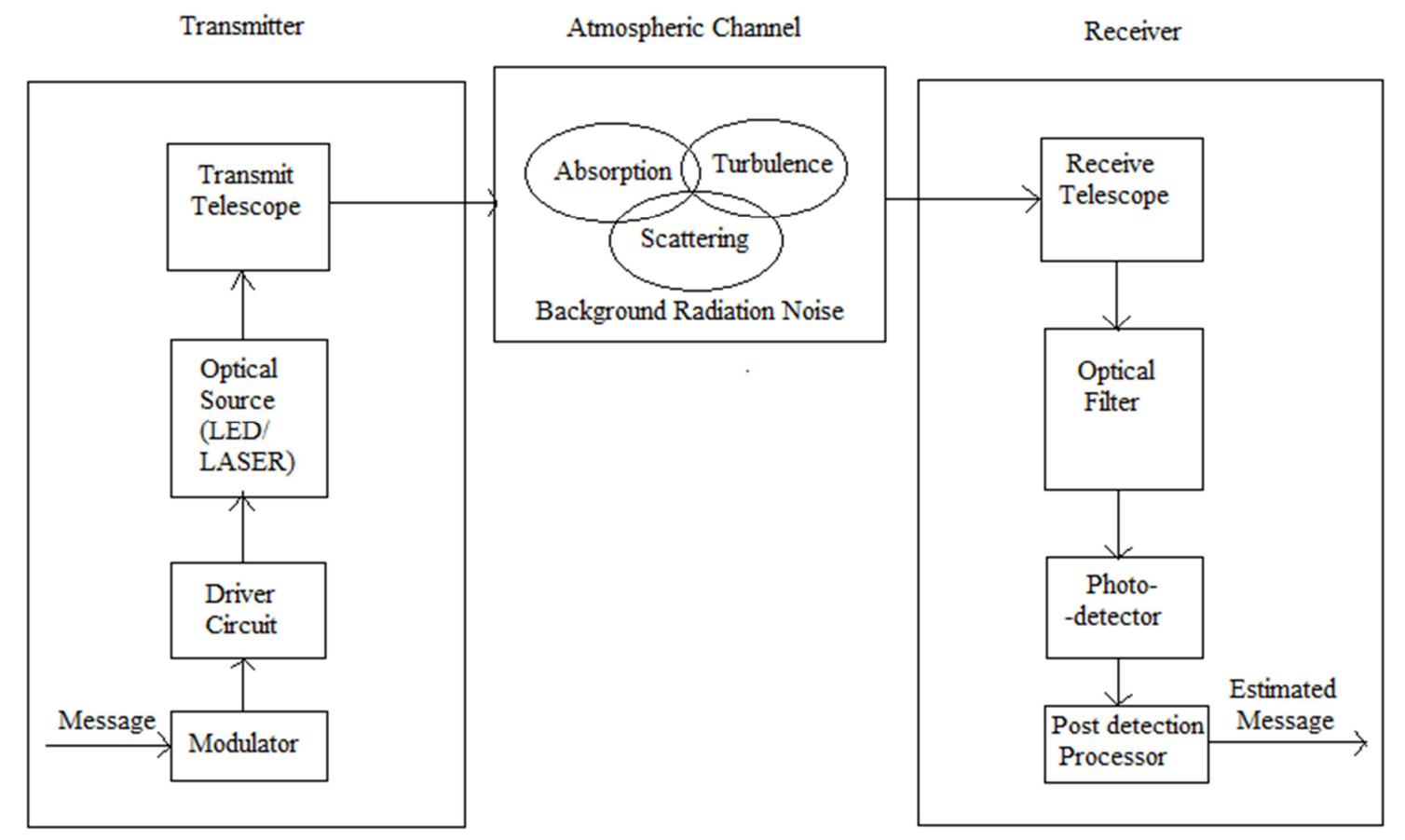

Figure 1. Block Diagram of FSO [8].

\subsection{Atmospheric Optical Channel [9-10]}

The atmospheric channel consists of gases, aerosols-tiny particles suspended in the atmosphere. Also present in the atmosphere are rain, haze, fog and other forms of precipitation. Another feature of interest is atmospheric turbulence. When radiation strikes the earth from the Sun, some of the radiation is absorbed by the earth's surface thereby heating up its (Earth's) surface air mass. The resulting mass of warm and lighter air then rises up to mix turbulently with the surrounding cooler air mass to create atmospheric turbulence. With the size distribution of the atmospheric constituents ranging from sub-micrometers to centimeters, an optical field that traverses the atmosphere is scattered and or absorbed [8].

\subsection{Optical Attenuation by Fog}

The combined effects of direct absorption and scattering of laser light can be described by a single path-dependent attenuation coefficient $\gamma(\mathrm{dB} / \mathrm{km})$ which is to be described by Kim and Kruse Models as given by [4].

Let $\lambda$ is the wavelength in $\mathrm{nm}, \mathrm{V}$ is the visibility $(\mathrm{m})$, and $\mathrm{q}$ is the particle size distribution. For kruse model

$$
\begin{aligned}
& 1.6 \text { if } \mathrm{V}>50 \mathrm{~km} \\
& \mathrm{q}=1.3 \text { if } 6 \mathrm{~km}<\mathrm{V}<50 \mathrm{~km} \\
& 0.585 \mathrm{~V} 1 / 3+0.34 \text { if } \mathrm{V}<6 \mathrm{~km}
\end{aligned}
$$

Equation (1) implies that for any meteorological condition, there will be less attenuation for higher wavelengths. The attenuation of $10 \mu \mathrm{m}$ is expected to be less than attenuation of shorter wavelengths. Kim rejected such wavelength dependent attenuation for low visibility in dense fog. The $\mathrm{q}$ variable in equation (1) for Kim model is given by

$$
\begin{aligned}
& 0.16 \mathrm{~V}+0.34 \text { if } 1 \mathrm{~km}<\mathrm{V}<6 \mathrm{~km} \\
& \mathrm{q}=\mathrm{V}-0.5 \text { if } 0.5 \mathrm{~km}<\mathrm{V}<1 \mathrm{~km} \\
& 0 \text { if } \mathrm{V}<0.5 \mathrm{~km}
\end{aligned}
$$

The advection fog is generated when the warm, moist air flows over a colder surface. The air in contact with the surface is cooled below its dew point, causing the condensation of water vapour. It appears more particularly in spring when southern displacements of warm, moist air masses move over snow covered regions.

The radiation or convection fog is generated by radiative cooling of an air mass during the night radiation when meteorological conditions are favourable (very low speed winds, high humidity, clear sky). It forms when the surface releases the heat that is accumulated during the day and becomes colder: the air which is in contact with this surface is cooled below the dew point, causing the condensation of water vapour, which results in the formation of a ground level cloud. This type of fog occurs more particularly in valleys.

\subsection{Optical Attenuation by Rain}

Rain is precipitation of liquid drops with diameters greater than $0.5 \mathrm{~mm}$. when the drops are smaller; the precipitation is usually called drizzle. The optical signal is randomly attenuated by fog and rain when it passes through the atmosphere. The main attenuation factor for optical wireless link is fog. However, rain also imposes certain attenuation. When the size of water droplets of rain becomes large 
enough it causes reflection and refraction. As a result these droplets cause wavelength independent scattering. Majority of the rain drops belong to this category. The increase in rainfall rate causes linear increase in attenuation, and the mean of the raindrop sizes also increases with the rainfall rate and is in the order of a few $\mathrm{mm}$. The other prediction model that has been recommended by ITU-R is as in Table 1 and other models that have been used for FSO rain attenuation prediction is as in Table 2.

Table 1. Rain Attenuation Prediction Model Proposed by ITU-R for FSO.

\begin{tabular}{lllll}
\hline Model & Origin & Author & K & $\boldsymbol{\alpha}$ \\
\hline Carbonneau & France & ITU-R [17] & 1.076 & 0.67 \\
Japan & Japan & ITU-R [17] & 1.58 & 0.63 \\
\hline
\end{tabular}

Table 2. Rain Attenuation Prediction Model for FSO.

\begin{tabular}{ll}
\hline Attenuation & Relation \\
\hline Drizzle or light rain (Joss) $(\mathrm{R}<3.8 \mathrm{~mm} / \mathrm{hr})$ & $0.509 \mathrm{R}^{0.63}$ \\
Mean rain (Joss) $(3.8<\mathrm{R}<7.6 \mathrm{~mm} / \mathrm{hr})$ & $0.319 \mathrm{R}^{0.63}$ \\
Strong rain (storm) (Joss) $(\mathrm{R}<7.6 \mathrm{~mm} / \mathrm{hr})$ & $0.163 \mathrm{R}^{0.63}$ \\
Rain (Marshal and Palmer) & $0.365 \mathrm{R}^{0.63}$ \\
\hline
\end{tabular}

\section{Simulation Based FSO Link Design}

The FSO link is designed and results are evaluated at $1550 \mathrm{~nm}$ wavelength. The simulation design of FSO is shown below (figure 2)

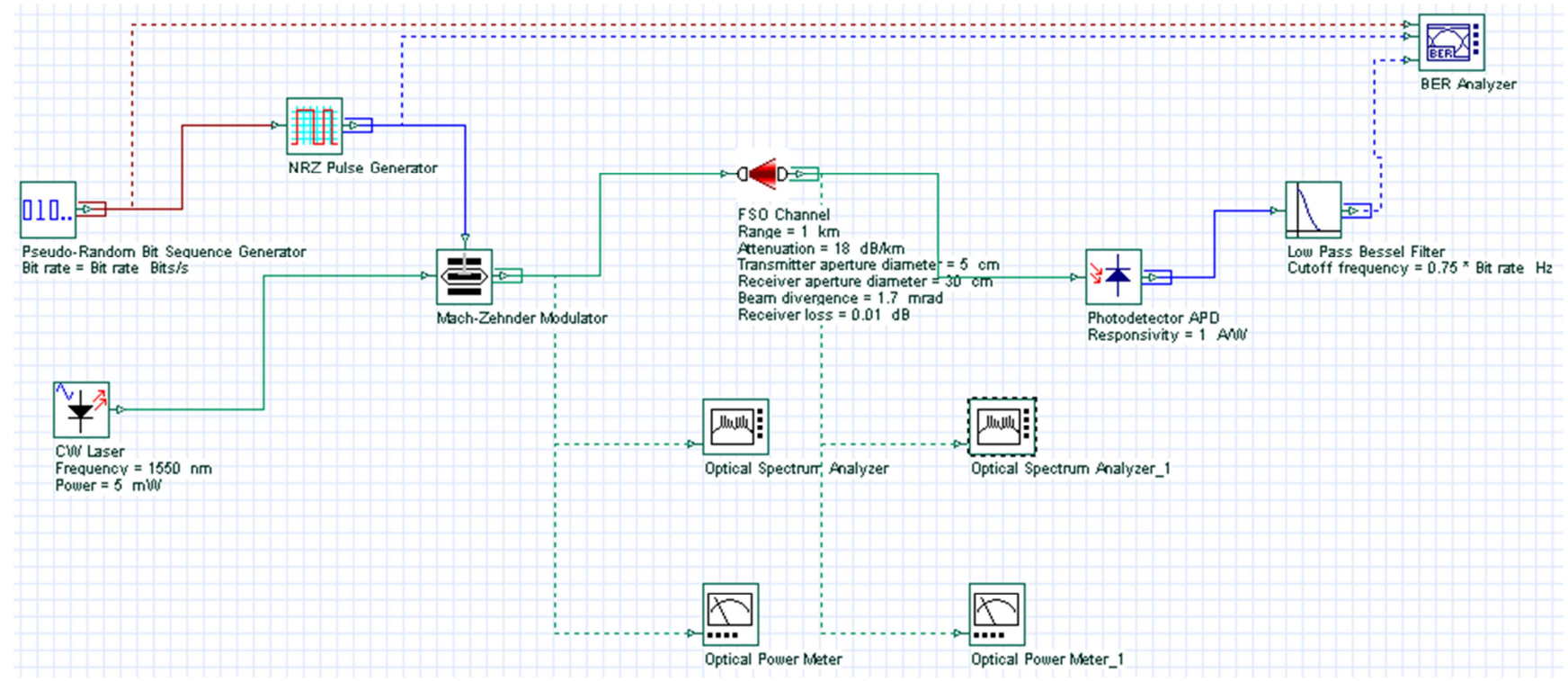

Figure 2. Optimized 1550nm FSO Link.

We have set the wavelength to $1550 \mathrm{~nm}$ that produces invisible laser beam. Next is the FSO channel in which provision is provided by simulator to change parameters of free space like link range, attenuation, beam divergence angle etc. To analyze the optical power, simulator provides power meter and spectrum analyzer tools. These are connected at transmitted and receiver to evaluate the performance of the link. The simulator proves to practical conditions as it provide provision for adjusting parameters like power transmitted, bit rate, noise bandwidth, range, geometric and additional losses, propagation delay and types of diodes along with their responsivity.

\section{Results \& Discussion}

Figure 3 shows the transmitted optical power and its spectrum with the wavelength of the optimized link for length 1000 meters. Optical power transmitted is $2.461 \mathrm{e}^{-3}$ Watts calculated by the power meter. The spectrum of the transmitted power in Figure 3 also shows at the peak wavelength of $1550 \mathrm{~nm}$. Optical power received is $1.209 \mathrm{e}^{-6}$ Watts as calculated by the power meter. 


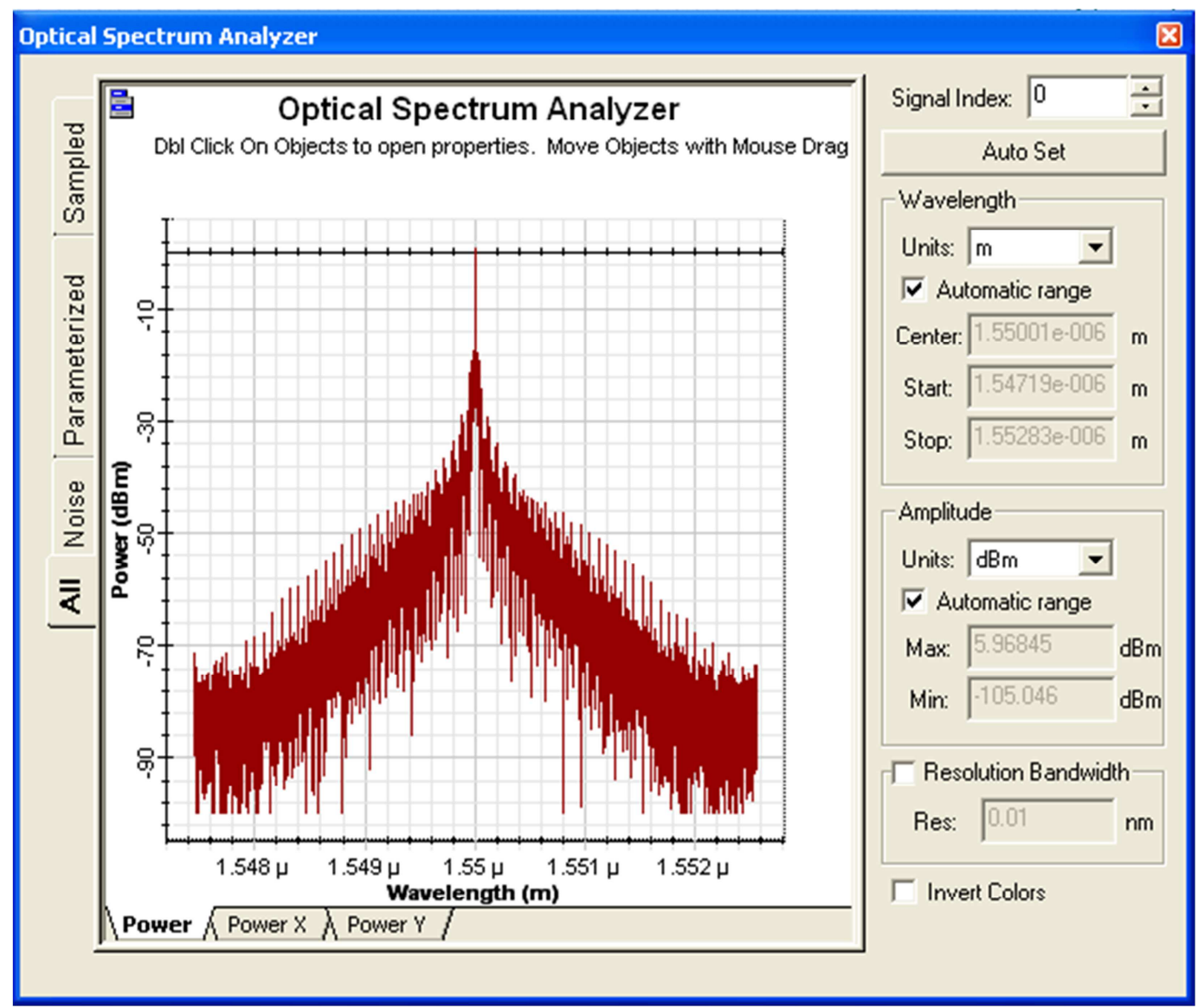

Figure 3. Transmitted Optical Power for link length 1000 meter.

\section{Conclusion}

The simulation work is done to analyze the FSO link performance at $1500 \mathrm{~nm}$ wavelength and at maximum distance of 1000 meters. The powers transmitted and received is analyzed by using the optical power analyzers. For FSO systems, mostly used modulation techniques are RZ (Return-to-zero) and NRZ (Non-return-to-zero). Therefore, in this research work, for FSO systems we prefer MachZehnder Modulator with an NRZ modulation technique.

\section{References}

[1] Anshul Vats, Hemani Kaushal "Analysis of free space optical link in turbulent atmosphere" Optik, Volume 125, 2014, Pages 2776-2779.

[2] Mazin Ali A. Ali, "Analysis of Data Rate for Free Space Optical Communications System" International Journal of Electronics \& Communication Technology (IJECT), Vol. 5, Issue Spl-1, Jan - March 2014, ISSN: 2230-7109 (Online) | ISSN: 2230-9543 (Print), Pages 20-23.

[3] Mazin Ali Abd Ali, Miami Abdulatteef Mohammed, "Effect of Atmospheric Attenuation on Laser Communications for Visible and Infrared Wavelengths" Journal of Al-Nahrain University, Vol. 16 (3), September, 2013, Pages 133-140.

[4] Mazin Ali Abd Ali, "Free Space Lasers Propagation at
Different Weather Conditions" Al Mustansiriyah J. Sci, Vol. 23, No 2, 2012, Pages 81-90.

[5] F. Nadeem, T. Javornik, E. Leitgeb, V. Kvicera, G. Kandus, "Continental Fog Attenuation Empirical Relationship from Measured Visibility Data" Radio engineering, Vol. 19, NO. 4, December 2010, Pages 596-600.

[6] Martin Grabner, Vaclav Kvicera, "Experimental Study of Atmospheric Visibility and Optical Wave Attenuation for Free-Space Optics Communications” Pages 1-4.

[7] M. Tatarko, L. Ovseník and J. Turán, "Availability and Reliability of FSO Links Estimated from Visibility" Carpathian Journal of Electronic and Computer Engineering Vol. 5, 2012, ISSN 1844 - 9689, Pages 121-126.

[8] Ghassemlooy, Z. and Popoola, W. O. "Terrestial Free Space Optical Communications" 2010, Pages 355-394, Salma Ait Fares and Fumiyuki Adachi (Ed.) "Mobile and Wireless Communications Network Layer and Circuit Level Design", ISBN: 978-953-307-042-1, InTech, January, 2010, Pages 404.

[9] N. Kaur, G. Soni, "Performance analysis of inter-satellite optical wireless communication (IsOWC) system at $980 \mathrm{~nm}$ and $1550 \mathrm{~nm}$ wavelengths", International Conference on Contemporary Computing \& Informatics (IC3I), pp. 1245$1250,2014$.

[10] Gaurav Soni, "A Performance Analysis of Free-Space Optical Link at $1550 \mathrm{~nm} 850 \mathrm{~nm} 650 \mathrm{~nm}$ and $532 \mathrm{~nm}$ Optical Wavelengths", Journal of Optical Communications, January 2017. 


\section{Biography}

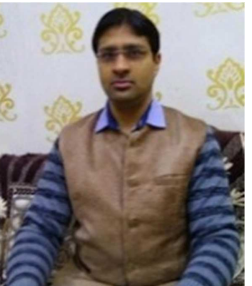

Gaurav Soni received his B-Tech Degree in ECE from PTU, Kapurthala in the year 2005 and M-Tech Degree in ECE from D. A. V. I. E. T, Jalandhar. He has more than ten years of teaching and research experience. He has to his credit 91 research papers in various refereed international journals like JOC and IEEE conference Proceedings. He is currently working as Associate Prof. in ECE Deptt., Amritsar College of Engineering and Technology, Amritsar. He has served as reviewer to IEEE Journal of Lightwave Technology, reviewer \& editor of Advances in Science, Technology and Engineering Systems Journal. 